\title{
Comparative analysis of septic injury-inducible genes in phylogenetically distant model organisms of regeneration and stem cell research, the planarian Schmidtea mediterranea and the cnidarian Hydra vulgaris Boran Altincicek* and Andreas Vilcinskas
}

Address: Interdisciplinary Research Center, Institute of Phytopathology and Applied Zoology, Justus-Liebig-University of Giessen, Heinrich-BuffRing 26-32, D-35392 Giessen, Germany

Email: Boran Altincicek* - Boran.Altincicek@agrar.uni-giessen.de; Andreas Vilcinskas - Andreas.Vilcinskas@agrar.uni-giessen.de

* Corresponding author

Published: 27 April 2008

Frontiers in Zoology 2008, 5:6 doi:10.1 I86/1742-9994-5-6
Received: I April 2008

Accepted: 27 April 2008

This article is available from: http://www.frontiersinzoology.com/content/5/1/6

(c) 2008 Altincicek and Vilcinskas; licensee BioMed Central Ltd.

This is an Open Access article distributed under the terms of the Creative Commons Attribution License (http://creativecommons.org/licenses/by/2.0), which permits unrestricted use, distribution, and reproduction in any medium, provided the original work is properly cited.

\begin{abstract}
Background: The planarian Schmidtea mediterranea and the cnidarian Hydra vulgaris have emerged as valuable model organisms in regeneration and stem cell research because of their prominent ability to regenerate a complete organism from any small body fragment. Under natural conditions wounding may result from predator attacks. These injuries open their innermost to a wide array of microbes present in the environment. Therefore, we established the hypothesis that regeneration processes may be linked to or at least accompanied by innate immune responses. In order to screen for septic wounding inducible genes we dissected individuals using a scalpel in the presence of a crude bacterial lipopolysaccharide preparation that is commonly used to elicit innate immune responses in animals and applied the suppression subtractive hybridization technique that selectively amplifies cDNAs of differentially expressed genes.
\end{abstract}

Results: This analysis revealed the induced expression of 27 genes in immune challenged Schmidtea and 35 genes in immune challenged Hydra. Identified genes from both animals encode proteins that share sequence similarities with potential homologues from other organisms known to be involved in signaling (e.g. calreticulin in Schmidtea and major vault protein in Hydra), stress responses (e.g. Hsp20 in Schmidtea and a PRPI9/PSO4 DNA repair protein in Hydra), or to represent potential antimicrobial effectors (e.g. perforin-like protein in Schmidtea and PR-I-like protein and neutrophil cytosolic factor I in Hydra). As expected, septic wounding also induces expression of genes in Schmidtea and Hydra potentially involved in tissue remodeling associated with regeneration processes (e.g. matrix metalloproteinase in Schmidtea and a potential von Willebrand factor in Hydra).

Conclusion: We identified numerous immune-inducible genes in Hydra and Schmidtea that show a similar distribution corresponding to their physiological roles, although lineages of both animals split from their common ancestor for more than five hundred millions of years. The present study is the first analysis of immune-inducible genes of these two phylogenetically distant model organisms of regeneration and provide numerous candidate genes that we can use as a starting point for comparative examination of interrelationships between immunity and homeostasis. 


\section{Background}

To date, there is no satisfactory answer to the question why some animals have higher regeneration capacities than others. The ability to replace lost or injured body parts is widely distributed among animals, whereas regeneration of a complete organism from any small body fragment is restricted to only few animal phyla and is accompanied by the ability to reproduce asexually by budding or fission $[1,2]$. These features have been attributed to a stable population of stem cells known as neoblasts in Schmidtea mediterranea [3,4] and to both stem cellbased mechanisms and transdifferentiation in Hydra vulgaris [5,6]. These two phylogenetically distant animals with remarkable regeneration capacities attract renewed attention as powerful model organisms since both, $S$. mediterranea and $H$. vulgaris, are amenable to systemic RNAi mediated gene silencing and other genetic tools for functional gene analyses [7-11].

In their habitats Hydra and Schmidtea may be wounded by attacks from predators. These natural injuries open their innermost to a wide array of microbes present in the environment. Therefore, we established the hypothesis that regeneration processes may be linked to or at least accompanied by innate immune responses. As a first step towards understanding the immune defense reactions of both model organisms we used the suppression subtrac- tive hybridization (SSH) technique. This method has been proven as a valuable tool for identification of novel immune-inducible genes in a number of animal species, including representatives of Ecdysozoa [12-18], Lophotrochozoa [19-22], and Deuterostomia [23,24]. Here, we applied the SSH method to identify genes that are differentially expressed upon wounding in Cnidaria and Platyhelminthes. We selected Hydra and Schmidtea for analyses because both are currently emerging as genetically tractable models in regeneration, development and stem cell research. In addition, their complete genome sequences have recently been determined and will be available soon $[25,26]$. The phylogenetic relationship between Hydra and Schmidtea and model organisms whose septic-injury inducible genes have previously been identified using the SSH-method supports comparative approaches to reconstruct evolution and function of genes that are linked to immunity (Fig. 1). Further reasons that make Hydra and Schmidtea amenable to comparative approach analyses are that both share similar body sizes and colonize freshwater habitats allowing comparable experimental conditions.

In this study, we report profiles of injury-inducible genes from Schmidtea and Hydra, including genes that encode proteins potentially involved in e.g. immune-inducible signaling and defense reactions. Comparisons of potential

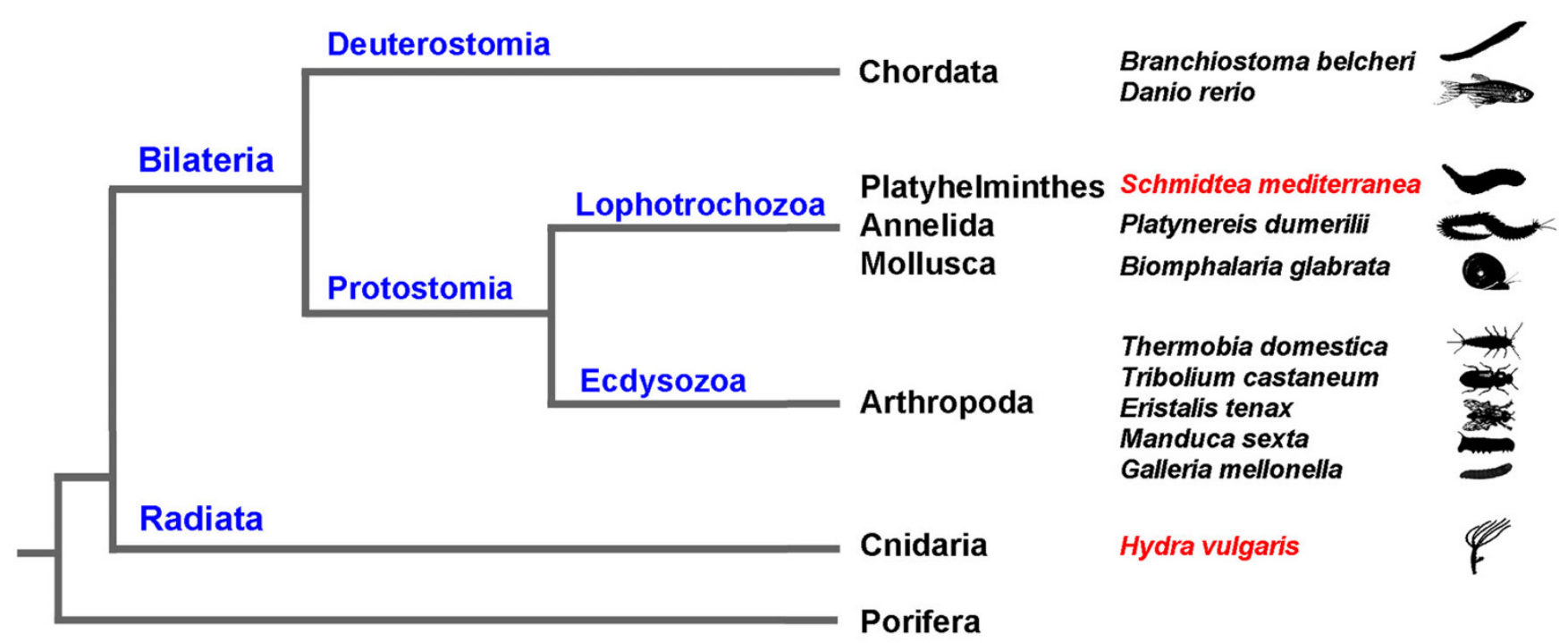

Figure I

Phyla distribution of animals whose immune-inducible genes have been analyzed by the SSH method. A major evolutionary divide occurs in the animal kingdom between the so-called radially symmetric animals, which includes the cnidarian Hydra, and the bilaterally symmetric animals, which includes Schmidtea. The phylogenetic position of these two model organisms that have been selected for investigations in the present work (indicated by red color) promotes comparative analysis that may help to reconstruct functions and evolution of genes involved in regeneration and immunity. Previously, Branchiostoma belcheri [23], Danio rerio [24], Platynereis dumerilii [19], Biomphalaria glabrata [20,2 I], Thermobia domestica [I2], Tribolium castaneum [14], Eristalis tenax [13], Manduca sexta [17], and Galleria mellonella [15] have been analyzed by the SSH method. 
calreticulin, matrix metalloproteinase (MMP), and perforin with homologues from other organisms provide novel insights into the ancestral complexity and evolution of the metazoan immune system.

\section{Results and Discussion}

Subtracted cDNA libraries of immune challenged S. mediterranea and $\mathbf{H}$. vulgaris

A subtracted cDNA library enriched in immune-inducible genes from $S$. mediterranea and $H$. vulgaris, respectively, was constructed by using the SSH method. A total of each 288 clones were randomly picked and subjected to colony PCR. Plasmids of bacterial colonies that have been screened positively in blot hybridization indicating induced expression of corresponding genes were isolated and sequenced. Here, we describe the identification of 27 septic wounding-inducible genes in $S$. mediterranea (Table 1) and 35 septic wounding-inducible genes in $H$. vulgaris (Table 2) potentially involved in antimicrobial defense, signaling, and other immunity-linked cellular processes (Fig. 2).

\section{Signaling}

In animals, hereditable receptors including the prominent Toll-receptors recognize damage- or pathogen-associated molecular pattern molecules and engage multiple immune-related signaling pathways [27]. Here, we identified a Schmidtea cDNA encoding a protein that exhibits highest sequence similarities to p21/Cdc42/Rac1-activated kinase 1 from Apis. In mammals, this kinase is believed to act directly on the JNK (c-Jun N-terminal kinase) MAP (mitogen-activated protein) kinase pathway
[28]. JNK is a prominent stress kinase that has been studied mostly in the context of cellular stress and apoptotic cell death following, for example, heat shock, DNA damage, and inflammation [29].

Calcium signals in human immune cells participate in the regulation of cell differentiation and influence lymphocyte motility, immunological synapse formation, degranulation and phagocytosis [30]. In agreement, we found several predicted proteins in Schmidtea and Hydra that show similarities to members of the calcium signaling pathways suggesting that calcium pathways may be important in immune responses in these animals. One Schmidtea protein with highest similarities to ferlin family proteins that are known to be associated with both plasma and nuclear membranes contains a C2 domain that may play a role in calcium-mediated membrane fusion events during membrane regeneration and repair [31]. Additionally, we identified a Schmidtea cDNA that encodes a potential calcipressin homologue. Vertebrate calcipressins modulate the pattern of calcineurin-dependent transcription, and may influence calcineurin activity beyond calcium to integrate a broad array of signals into the cellular response [32]. The importance of calcineurin in immunity is highlighted by the use of calcineurin inhibitors such as cyclosporine as prominent immunosuppressive drugs in humans [33]. Furthermore, we found a potential $S$ chmidtea phospholipase C that may generate inositol triphosphate and diacylglycerol by hydrolyzing phosphatidylinositol which in turn leads to raising the level of intracellular calcium. In Hydra, we determined the induced expression of a potential diacylglycerol kinase
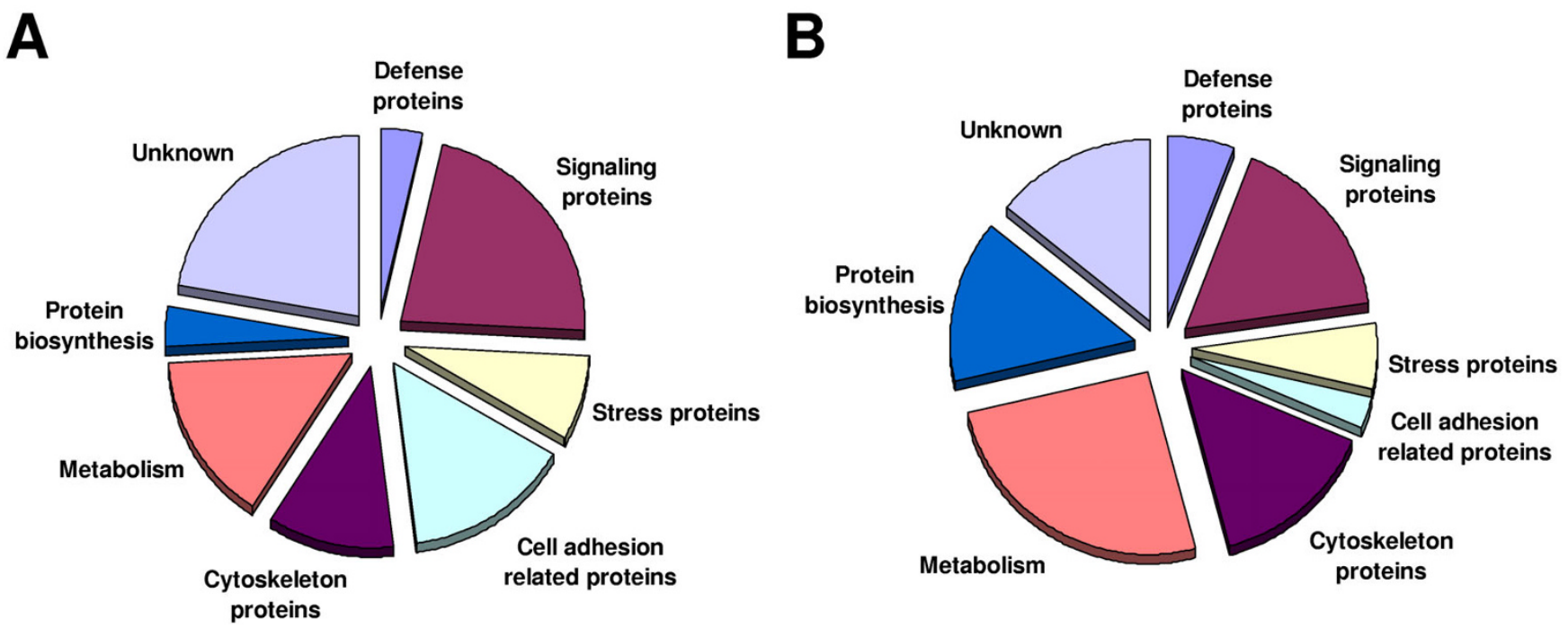

Figure 2

Distribution of immune-inducible transcripts identified by the SSH approach in Schmidtea and Hydra. Septic injury results in an immune-induced expression of totally 27 genes in S. mediterranea (A) and 35 genes in $H$. vulgaris (B) as obtained by the SSH approach. Interestingly, the genes have a similar distribution regarding their physiological roles. 
Table I: cDNAs from the subtracted S. mediterranea library.

\begin{tabular}{|c|c|c|c|c|}
\hline Cluster & GenBank Accession No. of EST & Highest BlastX match & Evalue & PFAM/InterPro \\
\hline \multicolumn{5}{|c|}{ Defense protein } \\
\hline & $\underline{F C 823226}$ & $\begin{array}{l}\text { AAR82935: macrophage expressed protein } \\
\text { (Haliotis corrugata) }\end{array}$ & $3 e-22$ & $\begin{array}{l}\text { Membrane attack complex component/ } \\
\text { perforin/C9 }\end{array}$ \\
\hline \multicolumn{5}{|c|}{ Signaling proteins } \\
\hline & $\underline{F C 823227}$ & $\begin{array}{l}\text { XP_00 I I I 9958: similar to P2I/Cdc42/Racl- } \\
\text { activated kinase I (Apis mellifera) }\end{array}$ & $2 e-35$ & P2I-activated kinase \\
\hline & $\underline{F C 823228}$ & $\begin{array}{l}\text { XP_972570: similar to PhosphoLipase C family } \\
\text { member (plc-I) (Tribolium castaneum) }\end{array}$ & $8 e-09$ & \\
\hline & $\underline{F C 823229}$ & $\begin{array}{l}\text { NP_524378: sarah CG6072-PA (Drosophila } \\
\text { melanogaster) }\end{array}$ & $5 e-23$ & Calcipressin \\
\hline & FC823230 & $\begin{array}{l}\text { CAK04334: similar to human chromodomain } \\
\text { helicase DNA binding protein } 2 \text { (CHD2) (Danio } \\
\text { rerio) }\end{array}$ & $6 e-53$ & DEAD-like helicases, $\mathrm{N}$-terminal \\
\hline & $\underline{F C 823231}$ & $\begin{array}{l}\text { XP_00I I } 97550 \text { : similar to mFLJ00 I } 75 \text { protein, } \\
\text { partial (Strongylocentrotus purpuratus) }\end{array}$ & $2 e-72$ & $\begin{array}{l}\text { C2 calcium-dependent membrane } \\
\text { targeting }\end{array}$ \\
\hline & $\underline{F C 823232}$ & $\begin{array}{l}\text { XP_392689: similar to Calreticulin CG9429-PA } \\
\text { (Apis mellifera) }\end{array}$ & $8 e-99$ & Calreticulin \\
\hline \multicolumn{5}{|c|}{ Stress related proteins } \\
\hline & $\underline{F C 823233}$ & $\begin{array}{l}\text { AAW25328: SJCHGC09367 protein (Schistosoma } \\
\text { japonicum) }\end{array}$ & $7 e-07$ & Hsp20/alpha crystallin family \\
\hline & $\underline{F C 823234}$ & XP_696859: hypothetical protein (Danio rerio) & $7 e-27$ & RAD50 \\
\hline \multicolumn{5}{|c|}{ Cell adhesion related proteins } \\
\hline & $\underline{\mathrm{FC} 823235}$ & $\begin{array}{l}\text { CAA37667: pre-pro-hatching enzyme } \\
\text { (Paracentrotus lividus) }\end{array}$ & $4 e-20$ & Peptidase_MIO \\
\hline & FC823236 & $\begin{array}{l}\text { AAX25986: SJCHGC09378 protein (Schistosoma } \\
\text { japonicum) }\end{array}$ & $3 e-52$ & Collagen triple helix repeat \\
\hline & FC823237 & $\begin{array}{l}\text { ZP_01611880: putative adhesion lipoprotein } \\
\text { (Alteromonadales bacterium TW-7) }\end{array}$ & $5 e-02$ & Beta-lg-H3/fasciclin \\
\hline & $\underline{F C 823238}$ & $\begin{array}{l}\text { AAX25800: SJCHGC02I } 49 \text { protein (Schistosoma } \\
\text { japonicum) }\end{array}$ & $4 e-06$ & Cell adhesion molecule \\
\hline \multicolumn{5}{|c|}{ Cytoskeleton proteins } \\
\hline & FC823239 & XP_4I 9249: hypothetical protein (Gallus gallus) & $2 e-64$ & Tubulin/FtsZ \\
\hline & $\overline{\mathrm{FC} 823240}$ & $\begin{array}{l}\text { XP_00II I6242: similar to cytoskeletal actin Cyllb } \\
\text { (Strongylocentrotus purpuratus) }\end{array}$ & $3 e-38$ & Actin \\
\hline & $\underline{F C 823241}$ & $\begin{array}{l}\text { XP_624678: similar to Myosin IA (MIA) (Brush } \\
\text { border myosin IA) (BBMIA) (Apis mellifera) }\end{array}$ & $8 e-61$ & $\begin{array}{l}\text { IQ calmodulin-binding region; } \\
\text { Myosin_head }\end{array}$ \\
\hline \multicolumn{5}{|c|}{ Metabolism } \\
\hline & $\underline{F C 823242}$ & $\begin{array}{l}\text { AAB53748: 3-hydroxy-3-methylglutaryl-CoA } \\
\text { reductase (Oryza sativa) }\end{array}$ & le- 14 & $\begin{array}{l}\text { Hydroxymethylglutaryl-coenzyme A } \\
\text { reductase }\end{array}$ \\
\hline & $\underline{F C 823243}$ & $\begin{array}{l}\text { CAF95654: unnamed protein product (Tetraodon } \\
\text { nigroviridis) }\end{array}$ & $2 e-21$ & Selenophosphate synthetase \\
\hline & FC823244 & $\begin{array}{l}\text { AAU03 I35: glutamate dehydrogenase (Hylobates } \\
\text { lar) }\end{array}$ & le-55 & Glu/Leu/Phe/Val dehydrogenase \\
\hline & $\underline{F C 823245}$ & $\begin{array}{l}\text { XP_00II I7763I: similar to Gldc-prov protein } \\
\text { (Strongylocentrotus purpuratus) }\end{array}$ & $4 e-52$ & Glycine cleavage system P-protein \\
\hline \multicolumn{5}{|c|}{ Protein biosynthesis } \\
\hline & FC823246 & AAL49199: RE63456p (Drosophila melanogaster) & $9 e-18$ & Ribosomal_L34e \\
\hline \multicolumn{5}{|c|}{ Unknown proteins } \\
\hline & FC823247 & $\begin{array}{l}\text { CAE65027: Hypothetical protein CBG09865 } \\
\text { (Caenorhabditis briggsae) }\end{array}$ & le-03 & \\
\hline & FC823248 & Hypothetical protein & NSM' & Ubiquitin \\
\hline & $\underline{F C 823249}$ & Hypothetical protein & NSM & \\
\hline & FC823250 & Hypothetical protein & NSM & \\
\hline & FC823251 & Hypothetical protein & NSM & \\
\hline & $\overline{F C 823252}$ & Hypothetical protein & NSM & \\
\hline
\end{tabular}

INSM, no significant match 
Table 2: cDNAs from the subtracted $H$. vulgaris library.

\begin{tabular}{|c|c|c|c|c|}
\hline Cluster & $\begin{array}{l}\text { GenBank Accession } \\
\text { No. of EST }\end{array}$ & Highest BlastX match & Evalue & PFAM/InterPro \\
\hline \multicolumn{5}{|c|}{ Defense proteins } \\
\hline & $\underline{F C 823190}$ & XP_001356627: GAI4264-PA (Drosophila pseudoobscura) & $5 e-07$ & $\begin{array}{l}\mathrm{SCP} / \mathrm{Tpx}-\mathrm{I} / \mathrm{Ag} 5 / \mathrm{PR}-\mathrm{I} / \mathrm{Sc} 7 \text { family of } \\
\text { extracellular domains }\end{array}$ \\
\hline & $\underline{F C 823191}$ & $\begin{array}{l}\text { XP_00I0636I2: similar to neutrophil cytosolic factor I (Rattus } \\
\text { norvegicus) }\end{array}$ & $7 e-35$ & $\begin{array}{l}\text { p47-phox (neutrophil cytosolic } \\
\text { factor I) }\end{array}$ \\
\hline \multicolumn{5}{|c|}{ Signaling proteins } \\
\hline & FC823192 & XP_690149: similar to diacylglycerol kinase eta2 (Danio rerio) & $4 e-18$ & \\
\hline & $\underline{\mathrm{FC} 823193}$ & $\begin{array}{l}\text { XP_00I20I8I5: hypothetical protein, partial (Strongylocentrotus } \\
\text { purpuratus) }\end{array}$ & $6 e-96$ & Major vault protein, $\mathrm{N}$-terminal \\
\hline & FC823194 & XP_00I489489: similar to THO complex 4 (Equus caballus) & $6 e-06$ & \\
\hline & $\overline{\mathrm{FC} 823195}$ & $\begin{array}{l}\text { AAZ99727: dickkopf-like protein Dlp-I precursor (Hydra } \\
\text { magnipapillata) }\end{array}$ & $4 e-44$ & \\
\hline & $\underline{F C 823197}$ & $\begin{array}{l}\text { XP_421629: similar to Transmembrane } 9 \text { superfamily protein } \\
\text { member } 3 \text { precursor (Gallus gallus) }\end{array}$ & 2e-79 & Nonaspanin (TM9SF) \\
\hline & FC823198 & Q6NZZ4: Transmembrane protein 107 (Danio rerio) & $3 e-21$ & \\
\hline \multicolumn{5}{|c|}{ Stress related proteins } \\
\hline & FC823199 & XP_8679|3: similar to PRPI9/PSO4 homologue (Canis familiaris) & $|e-9|$ & WD40/YVTN repeat-like \\
\hline & FC823200 & AAM76192: LD3624IP (Scythe protein) (Drosophila melanogaster) & $5 e-03$ & \\
\hline \multicolumn{5}{|c|}{ Cell adhesion related proteins } \\
\hline & $\underline{F C 823201}$ & $\begin{array}{l}\text { AAT37632: von Willebrand factor (Branchiostoma belcheri } \\
\text { tsingtaunese) }\end{array}$ & $4 e-11$ & \\
\hline \multicolumn{5}{|c|}{ Cytoskeleton proteins } \\
\hline & FC823202 & EAW96898: myosin, light polypeptide 6B, (Homo sapiens) & $1 \mathrm{e}-10$ & Calcium-binding EF-hand \\
\hline & FC823203 & CAA48796: actin (Podocoryne carnea) & $3 e-116$ & Actin/actin-like \\
\hline & FC823204 & PI8320: Profilin (Anthocidaris crassispina) & $5 e-41$ & Profilin/allergen \\
\hline & $\overline{\mathrm{FC} 823205}$ & P34032: Thymosin beta-4 (Oryctolagus cuniculus) & $6 e-05$ & Thymosin beta- 4 \\
\hline & $\overline{\mathrm{FC} 823206}$ & $\begin{array}{l}\text { CAM37732: flagellar calcium-binding protein, putative (Leishmania } \\
\text { braziliensis) }\end{array}$ & $7 e-16$ & Calcium-binding EF-hand \\
\hline \multicolumn{5}{|c|}{ Metabolism } \\
\hline & $\underline{F C 823207}$ & $\begin{array}{l}\text { XP_00I366I87: similar to NADH dehydrogenase (Monodelphis } \\
\text { domestica) }\end{array}$ & $6 e-02$ & NADH dehydrogenase \\
\hline & $\underline{F C 823208}$ & XP_395823: similar to Phosphomannomutase (Apis mellifera) & le-25 & Phosphomannomutase \\
\hline & $\underline{F C 823209}$ & $\begin{array}{l}\text { XP_00I I 197762: similar to NAD(P)H:quinone oxidoreductase } \\
\text { (Strongylocentrotus purpuratus) }\end{array}$ & le-15 & Oxidoreductase \\
\hline & $\underline{F C 823210}$ & XP_00I494492: hypothetical protein (Equus caballus) & $3 e-15$ & MoeA, N-terminal, domain I and II \\
\hline & FC823211 & XP_783I97 hypothetical protein (Strongylocentrotus purpuratus) & $3 e-24$ & Methyltransferase type II \\
\hline & $\mathrm{FC} 823212$ & NP_001017016: exosome component 6 (Xenopus tropicalis) & $8 e-05$ & $\begin{array}{l}\text { Exonuclease, RNase T and DNA } \\
\text { polymerase III }\end{array}$ \\
\hline & $\underline{\mathrm{FC} 823213}$ & NP_957038: small fragment nuclease (Danio rerio) & $3 e-50$ & Ribonuclease $\mathrm{PH}$ related \\
\hline & $\overline{\mathrm{FC} 823214}$ & NP_99045I: enolase I (Gallus gallus) & $3 e-99$ & Enolase \\
\hline & FC823215 & $\begin{array}{l}\text { ABC25045: mitochondrial succinate dehydrogenase flavoprotein } \\
\text { subunit (Hydra vulgaris) }\end{array}$ & $4 e-94$ & $\begin{array}{l}\text { Fumarate reductase/succinate } \\
\text { dehydrogenase flavoprotein, }\end{array}$ \\
\hline \multicolumn{5}{|c|}{ Protein biosynthesis } \\
\hline & FC823216 & $\begin{array}{l}\text { AAR09792: similar to Drosophila melanogaster elF-5A } \\
\text { (Drosophila yakuba) }\end{array}$ & $2 e-06$ & elF-5A \\
\hline & FC823217 & NP_0010167|4: ribosomal protein L28 (Xenopus tropicalis) & $8 e-15$ & Ribosomal protein L28e \\
\hline & FC823218 & AAY434II: ribosomal protein L23 (Phytophthora infestans) & $4 e-34$ & Ribosomal protein LI4b/L23e \\
\hline & $\overline{\mathrm{FC} 823219}$ & XP_392565: similar to Ribosomal protein LI8 (Apis mellifera) & $4 e-60$ & Ribosomal protein LI8e \\
\hline & $\underline{F C 823220}$ & $\begin{array}{l}\text { AAY97868: cytoplasmic ribosomal protein SI3 (Lycopersicon } \\
\text { esculentum) }\end{array}$ & le-47 & Ribosomal protein SI5 \\
\hline \multicolumn{5}{|c|}{ Unknown proteins } \\
\hline & FC823221 & XP_4I3837: hypothetical protein (Gallus gallus) & $6 e-02$ & \\
\hline & $\underline{F C 823222}$ & $\begin{array}{l}\text { ZP_01629577: hypothetical protein (Nodularia spumigena } \\
\text { CCY94/4) }\end{array}$ & $9 e-02$ & \\
\hline & FC823223 & Hypothetical protein & NSMI & \\
\hline & FC823224 & Hypothetical protein & NSM & \\
\hline & $\overline{\text { FC823225 }}$ & Hypothetical protein & NSM & \\
\hline
\end{tabular}

'NSM, no significant match 


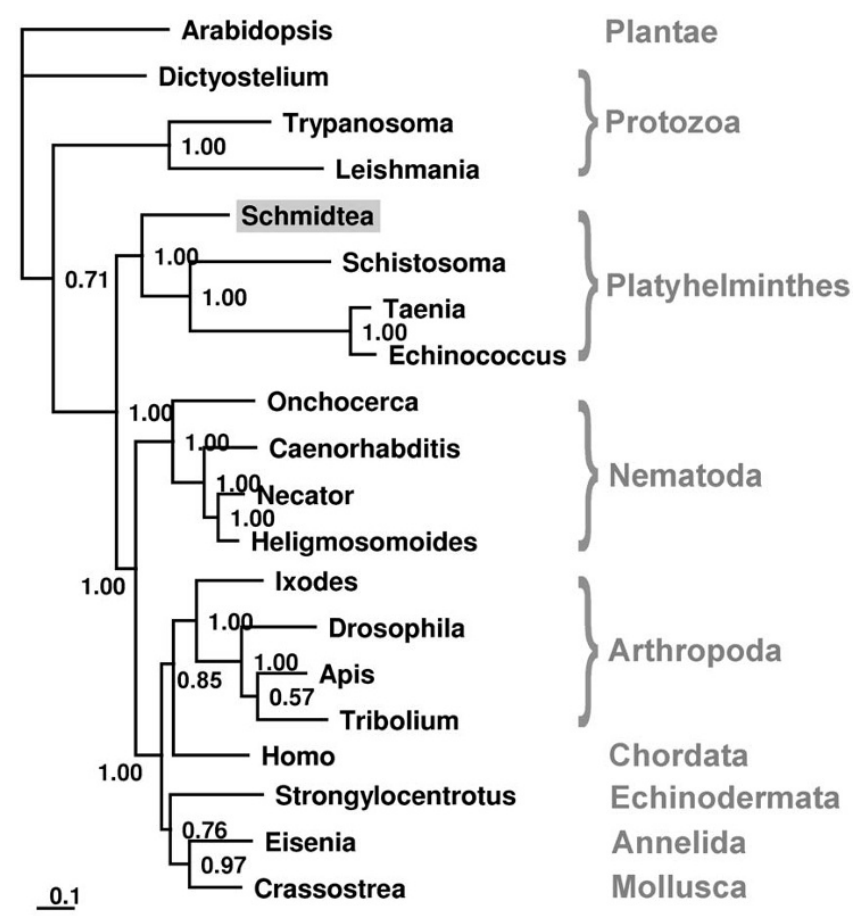

Figure 3

Phylogenetic analysis of Schmidtea calreticulin and homologues from selected species. We identified a calreticulin protein in the Schmidtea cDNA library. Using corresponding EST sequence and further EST sequences from the public database (DN3 I6I26 and EG4 I7940) we constructed the potential full-length protein. A Bayesian protein tree was generated using calreticulin sequences from Schmidtea and from selected species (Trypanosoma cruzi, EAN82340; Leishmania infantum, XP_001467584; Dictyostelium discoideum, XP_639010; Eisenia fetida, ABI746 I8; Schistosoma japonicum, ABK34456; Taenia solium, AAK52725; Echinococcus granulosus, AAX73173; Apis mellifera, XP_392689; Drosophila melanogaster, NP_524293; Tribolium castaneum, XP_971763; Crassostrea gigas, BAF63639; Onchocerca volvulus, AAA59056; Necator americanus, CAA07254; Heligmosomoides polygyrus, CAL30086; Caenorhabditis elegans, NP_504575; Ixodes scapularis, AAT99573; Homo sapiens, NP_004334; Strongylocentrotus purpuratus, NP_999643). As outgroup we selected plant Arabidopsis thaliana calreticulin (NP_00I03I I99). This phylogenetic analysis reveal that calreticulins are evolutionarily conserved and that Schmidtea calreticulin (indicated by gray shading) form an own group with calreticulins from parasitic Platyhelminthes. The scale bar represents the substitutions per site.

that balances between two signaling lipids, diacylglycerol and phosphatidic acid, by phosphorylating the former one. Therefore, diacylglycerol kinases may be involved in numerous lipid and calcium signaling pathways on transient or continuous demands, respectively [34].
In line with these findings, we identified a Schmidtea calreticulin homologue which is evolutionarily conserved (Fig. 3). Although originally characterized as a regulator of calcium homeostasis, more recently it has been shown to be present on the surface of many mammalian cell types and has been implicated in signal transduction events associated with innate immunity, cell adhesion, angiogenesis, and apoptosis [35]. In regard to its immune functions, cell surface levels of calreticulin directly correlate with the ability of human dentritic cells and polymorphonuclear phagocytes to mediate phagocytosis, and the capacity of normal and tumor cells to adhere to components of the extracellular matrix [35]. Furthermore, calreticulin has recently been demonstrated to play a crucial role in the loading of MHC class I molecules with optimal peptide cargo in mammals [36]. This is a clear example of ancient mechanisms co-opted by new ones such as the acquired immunity of vertebrates in the context of the evolution of the immune system. However, calreticulin is also a prominent stress-inducible molecular chaperone in the endoplasmatic reticulum. This is in agreement to our further identification of stress-related proteins, including a potential Hsp20/ $\alpha$-crystallin protein and a RAD50 DNA repair protein from Schmidtea and a PRP19/PSO4 DNA repair protein and a scythe protein (also known as Bat3) in Hydra. The latter one is an important regulator of the apoptogenic mitochondrial intermembrane protein AIF (Apoptosis-Inducing Factor) in mammals [37] and may have similar functions in Hydra.

\section{Defense molecules}

In this study we describe for the first time a platyhelminth protein with a relationship to the mammalian perforin, the macrophage-expressed protein, (Fig. 4) that probably functions in the Schmidtea innate immune system. Similar proteins have also been identified in porifera and cnidaria $[38,39]$ suggesting that perforins are evolutionarily conserved defense molecules. That also applies for an identified Hydra PR-1 (pathogenesis-related proteins-1) protein that shares sequence similarities with immuneinducible plant PR-1 proteins. The PR-1 family is strongly conserved in plants, fungi, insects, and vertebrates, including humans, and some recent studies suggest a role as signaling or effector molecule in antifungal defense reactions in plants [40].

Generation of reactive oxygen species by phagocytes is an essential mechanism of mammalian host defense against microbial infections. Several protein kinase C isoforms have been found to phosphorylate p47phox (neutrophil cytosolic factor 1), resulting in its membrane translocation and activation of the NADPH oxidase [41]. Here, we identified a Hydra protein with highest similarities to p47phox from other animals suggesting that generation of reactive oxygen species may also be important for anti- 
Schmidtea

Haliotis

Homo

Danio

Suberites

Schmidtea

Haliotis

Homo

Danio

Suberites

Schmidtea

Haliotis

Homo

Danio

Suberites

Schmidtea

Haliotis

Homo

Danio

Suberites

Schmidtea

Haliotis

Homo

Danio

Suberites

Schmidtea

Haliotis

Homo

Danio

Suberites

Schmidtea

Haliotis

Homo

Danio

Suberites

Schmidtea

Haliotis

Homo

Danio

Suberites

MYIQIILIISLFKILVKGSNEVNTIKDAYQLCQ-IMPNQRTFDVLPGSGWDNLANIGMGRILDLNESK MLGFVLVVSIVASVSGGEILDSVKKPEFPKGDVRACYGDNKKL.ERFEVILPGQGWDNLRNVDAGLVVVYNYSR MNNERATILFWAAAAWAKS-GKPSGEMDEVGVOKCK-NALKLPVLEVLPGGGWDNLRNVDMGRVMELTYSN MKSRAFHIIMLCCFISVC-NLHPLIRPNNGLRLCR-KNSSLTALEVLPGGGWDNLRNIDMCRVMNLSYSQ MVCLTRQIGSLTDTHPTNKLVMVGGGGGAGGLISLVSGALSGGGNIRAGAPRNMYPRGDPRNCLSGNPKLNILOVVPGIGWDNLRNSETGILTSFSYSQ CSFSNDNKYLIPNQLAIYPEKSSQVEISSEIFRHFSNYTSMSSQSINVGAEGGYGIFKIGGSFSTENIKIKSDQMETKSIFTRVQLRYLGFQSMFEPDTP CRTTEDGRYLIPDTVNTIPLKASKLNVYAELISHWSSYTSTTAHGVNVDAGLKYDSVQVSGKFSSGYESVKSKOIGDKSYTTRVQLRYVRYSAKLQPDAS CRTTEDGQYIIPDEIFTIPQKQSNLFMNSEILESWANYQSSTSYSINTELSI-F-FSKVNGKFSTEFQRMKTLQVKDQAITTRVQVRNLVYTVKINPTLE CQTTED GVYLIPDEVEVIPQKVSGVETNSEITMSWLEQKSSTSSSVNADVSF-F -FSVLNAKF STENQRMKTHOVKEGSVTARVQVRNHLYTVKAYPDFT CKVTYDRRYLIPDETFAIPIKTSTIDYQAELFDHWDAYKSVTSRSINAGFDF--FGKIGG membrane-attack complex / perforin-domain

LYPTFKNRTMDIAGLVVENKDSLYPEYLADMIVRDYGTHVIRAIDAGAILSKTDALNSOYVKKYESDSSTISVSASASFLSLFKI-DGKYOTKITQINI LHPTFKIRLISIAGSLQLNKID-QARYDSELLVRDFGTHVVTSVDAGAALVQEDQVSSEHFVNSRKFTKNQITAGASASLFGIFSI-DVSYHSSTSNEVK LSSGFRKELIDISDRL.ENNQTR-MATYL_AELLVLNYGTHVIISVDAGAALIQEDHLRASFLODSQSSRSAVIASAGLAFQNIVNF-KFFENYTSONVLT IDSRFAKOAEEIADAIENNQTR-HANYLSEKLVLDYGTHVITSVDAGATLVQEDYLKMSYISNSQSDKSSVSASAGANFFDKVKF-DIGGNTSQGSSQS EILSLIKSNDTE-SADYAAQILIRDYGTHCITSIDAGAVLIKEDNLKSTIMSNYKGRADSLSTAAGVEFYDMLKLRASAGFSSYSGDSDL

DEFNHNVVKTHIDTVGGAIFGAN-TSLSDWENSVMNNLVPIDRRGEPLYYAITPRAL-PEIDQET-VHKIYVLIKKAILRYYTANGRIGCLDIYSSPNFNP KAYEQSRSSSQIDTLGGPMFKASNFTANDWTNEVDHELVAVDRSGDPLFFLINSASL-PELPNSV-LYQLQNLVEETILHYYEFNTYRGCTELDSPNESP KSYLSNRTNSRVQSIGGVPFYPG-ITLOAWQOGITNHLVAIDRSGLPLHFF INPNML-PDLPGPL-VKKVSKTVETAVKRYYTFNTYPGCTDLNSPNFNF SSYQGNITYSLIQSHGGALFYPG-ITLOKWQQSTLNNLVAIDRSGLPLHYFLNPSTF-PDIPTPT-VNKLASTVRKAAERYYKVNTIPGCVNVDSPNFNF KAYRONRTSSRLYTYGGPPYKLG-MNLSRWENDIMNNLVATDRSGKPSHSLSTTOSLKPEVITSOEVFLIRRLVKSAVSOYYHYNTHTGCKNPKAPNLDH

DANIDS-GNCEHPSVNFTFGGTYQVC-__-GGPACGPYAQVNPLTGGFSCPSGFISIKLHSGLVRCDES-C-CHG-WWEW-_-_-RSCDTTC AANLDD-GTCKSPYTNLTFGGVYQTCSMSSGSNNGDLCSGLDQVNPKTGGHTCPDGYESVEL_HTGRLSDSKSVHSCHS-CWLFF-_-_-_-KCCHDNY QANTDD-GSCEGKMTNFSFGGVYOECTQLSGNRDVLCCOKLEOKNPLTGDFSCP SGYSPVHLLSQIHEEGYNHIECHRKCTLLVF-_-CKIVCEDVF QANVDD-ASCEGPITNLSFGGIYQRCTPLTPDGNII-CDETAQKNPATGGYSCPQHYNITLLHSEIVEKGFNHYECHTHCHSCGFLGLSTCCDKTCGDSY QTNNGAPGVCKEPSANYTFGGVESCR---SNGNDICGKLIOKNPLTGGYSCPKNEKALLIQLGIERSHKMRRVCVWKRKCTFFV-FNCHDVDDCTFVP

SY_-_FTTFWCYPVNIGPNYNGYQFGGI-___-RQGSCPIGYIPLK-VGLSIEICVTVDADPFNPYAIKFGGFFSCSAGNPIAQEYVKNKPKLY YHSEATYIMHWCAATGPVSQDSGYLFGGLYTSQLNNPLTQGKTCPVNEYT-RTLGKDLHICISDDYELGMKYSMPFGGFISCTTGNPLAMNPKPKSKGDM QVAKAEFRAFWCVASSQVPENSGLLFGGLFSSKSINPMINAQSCPAGYFPL_RLFEN-LKVCVSQDYELGSREAVPFGGFFSCTVGNPLVDPAISRDLGAL HVRRAKLETLWCSSTHKTPENSGYLFGGLFGPGIONPLTKSSSCPPSYFTQRFLSNGMMICMSNDYEIGTRESVPFAGFFSCQSGNPLSNSVEIASYQTYWCAPNKKNPPKFGYMFGGIYSNDIQNPITRSCSCPTHFLPLR-MGERATVCVSEDYELGHQFSLPFGGFFSCVSGNVI_AGNGSSE-_-_

SS-_-SKMADLKYWPKTCAKGYVAHISSIEQGCQISYCTETNKVSFGPLPRIIKPPFISIDYNPNSTK-VLIFTTKNGETFIKDN-VGSWKLFDIQ NSALPSLHSSFOGSKTWPKHCPKGYSQHLAYVDQGCEINYCLLAGSLSEVGLPKIRRPPFQTAPLIIPSTENHVVF-DPVILTWRKNQEAMQFISARVG SL-_KKCPGGF SQHPALISDGCQVSYCVKSGLFTGGSLPPARLPPFTRPPIMSOAATNTVIVINSENARSWIKDSQTHQWRLGEPI

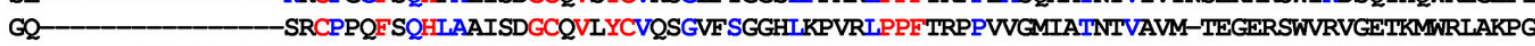
- FLNNPKDWPMRCPGGFTQHL_ALTEKGCRVNECVKAGSLIRASDLELVLPPFDPKPTLRKNSTSDLFSKPAVAPSGSLPIKGVPPPLDNNRV

REKR-_-NMLVGSIVGSFIMAACICLTIFFIQRRHYKRMIEKLDYKPLTNNEQL_ADYGSINNIDRV EATPSST-_-GSGMSAGAAAGIAVVATLGCVVISTVIVVLIKRRRKSSAGYRHLAIDDPLLSPQSNYGATGSDTVNVHVE ELRRAMNVIHGDGGGLSGGAAAGVIVGVITILAVVVIT-LAIYGTRKFKKKAYQAIFERQSLVPGTAATGDTTYYQEQGQSPA DIKQMOSIL-DASEMSGGKKAGVAIGIIVLVALVVAGTVVIMKRRNRF SSLKLNRGYEEISEGRNESSVEIEQEQNEAANENPNQQLLS IMYYPVLSSNTGQRDNGVGRITEPFFCHSWDWSVDLSVAHQATDKFAFAK

\section{Figure 4}

A potential perforin exist in Schmidtea that is related to other known perforins. We identified a perforin-like protein in the Schmidtea cDNA library. Using corresponding EST sequence and further EST sequences from the public database (DN313739, EG34397I, DN2994I2, DN307006) we constructed the potential full-length protein. The alignment with perforin sequences from Haliotis corrugata (AAR82935), Homo sapiens (AAII223I), Danio rerio (XP_6882I4), and the sponge Suberites domuncula (CAI680 I8) reveal that perforins are conserved in evolution. Red color indicates $90 \%$ consensus and blue color $40 \%$ consensus.

microbial defense in Cnidaria. In addition, we determined several short open reading frames in Schmidtea and Hydra that may encode potential antimicrobial peptides or signaling molecules. For example, one identified cDNA encodes a putative antimicrobial peptide that is cationic with potential $\alpha$-helical structure. It shows significant similarities to antimicrobial esculentin-1B from the frog Rana esculenta (Fig. 5). This is in agreement with our observations that $H$. vulgaris homogenates display inducible antimicrobial activities as determined by the inhibition zone assay against live Micrococcus luteus bacteria (data not shown).

Interestingly, one immune-inducible transcript from Hydra exhibits significant sequence similarities to major vault proteins from other organisms. Very recently, major 


\section{Hydra RLIKRPVFEKHGLGIISGLITIYGFSKIPVTDEMRKNSLTWNPYRIGIEEPHHHWIRSLASLSEDN Rana GIFSKIAGKKLKNLLISGLKNVGKEVGMDVVRTGIDIAGCKIKGEC}

\section{Figure 5}

A potential antimicrobial peptide in Hydra. We identified a Hydra cDNA (FC823225) that encodes a cationic peptide with predicted $\alpha$-helical structure [67]. It shares significant similarities with antimicrobial esculentin-IB (P40844) from Rana esculenta.

vault protein were found to be rapidly recruited to lipid rafts when human lung epithelial cells are infected with Pseudomonas aeruginosa. Major vault protein has been demonstrated to be essential for optimal epithelial cell internalization and clearance of $P$. aeruginosa indicating that it makes a substantial contribution to epithelial cellmediated resistance to infection in mammals [42] and probably also in Cnidaria. However, the group of Thomas C.G. Bosch has recently described that in Hydra, similar as in humans, the immune system maintains a substantial resident beneficial microbiota on their epithelia [43]. This suggests that Hydra is able to discriminate 'friend' from 'foe' by killing entities that do damage and let those live that are commensals or mutualists which is in agreement to Poly Matzingers' proposed danger model of mammalian immunity [44] and our recent findings from insects that endogenous alarm signals induce innate immune responses during infection $[45,46]$.

\section{Cellular homeostasis, cell adhesion related proteins, and regeneration}

We identified several Schmidtea and Hydra proteins potentially involved in cellular homeostasis such as ribosomal proteins, myosin, actin, tubulin and metabolic proteins including Schmidtea isoprenoid biosynthesis enzyme 3-hydroxy-3-methyl-glutaryl-CoA reductase (HMG-CoA reductase) and Hydra glycolytic enzyme enolase. This may reflect the need of an increased cellular metabolism during tissue regeneration. In addition, we determined a Hydra dickkopf-like protein that is potentially involved as an antagonist in Wnt signaling [47]. Confirming our result, a recent study demonstrated that the Hydra dickkopf-like protein expression is stimulated by the injury signal itself [48]. In vertebrates, wound healing and formation of a specialized wound epidermis require $\mathrm{Wnt} / \beta$-catenin signaling and, additionally, the action of matrix metalloproteinases (MMPs) [49]. In line with this, we identified a septic-injury inducible MMP homologue in Schmidtea that is evolutionarily conserved (Fig. 6). In Hydra, MMPs were shown to be required in extracellular matrix degradation and epithelial morphogenesis [50,51]. Members of this evolutionarily conserved family of enzymes play well-established multifaceted roles in tissue remodeling due to their capacity to degrade the extracellular matrix [52] and have recently been recog- nized as important modulators of immunity both in mammals [53] and in insects [54].

In addition, we found a Hydra protein with highest similarities to vWF (von Willebrand factor) proteins from other animals. This vWF protein is crucial for vertebrate blood clotting by binding to platelet receptors and collagens [55] and, in Hydra, may be important for cell-cell or cell-basement membrane adhesion processes.

Finally, we performed quantitative real time RT-PCR analyses using RNAs from untreated and immune challenged Schmidtea to precisely determine expression levels of several selected immune-inducible genes that were identified in the present study. This analysis confirmed the statictically significant induced expression of HMG-Co-A reductase, calreticulin, Hsp20, MMP, and perforin in response to septic injury (Fig. 7). The mRNA levels of tubulin and actin genes were elevated upon wounding but without statistically support due to higher variations of results from different determinations.

\section{Conclusion}

Here, we report a comparative analysis of immune-inducible genes in two phylogenetically distant model organisms of regeneration and stem cell research. We selected the cnidarian $H$. vulgaris and the planarian S. mediterranea for targeted screening of genes that are up-regulated upon large-scale septic wounding using the SSH method. Obtained results highlight the ancient origin of some genes (e.g. MMPs, calreticulin, p47-phox, perforin, and major vault protein) known from vertebrate immunity. This is consistent, for instance, with the findings that even the most ancient animals, porifera, possess functional Toll-like receptors [56] and with the recent report of a bioinformatic analysis of the immune repertoire in Cnidaria [39]. However, screening for immunity-related genes in genomic or EST databases only allows identification of genes that share sequence similarities with known genes, while the SSH-approach is particularly suitable for the experimental screen for yet unknown or unexpected genes and, therefore, complement the bioinformatic approaches. Confirming this, the present study increases the number of genes identified in Schmidtea and Hydra (e.g. phospholipase C and perforin for S. mediterranea and 
A

Schmidtea HEMGHAIGLHHSNDPSALMAPWY Hydra HEIGHSIGIEHSNVKEALMFPWY

Droso. 1 HEFGHSLGLSHSDQSSALMAPFY Droso.2 HELGHSLGLAHSAIPDAVMFPWY Human1 HELGHSLGLSHSTDIGALMYPSY Human2 HFFGHAMGLEHSQDPGALMAPIY Human3 HEIGHSLGLFHSANTEALMYPLY Human7 HELGHSLGMGHSSDPNAVMYPTY Human8 HFFGHSLGLAHSSDPGALMYPNY Human9 HFFGHALGLDHSSVPEALMYPMY Human10 HELGHSLGLFHSANTEALMYPLY Human11 HFFGHVLGLQHTTAAKALMSAFY Human12 HEIGHSLGLGHSSDPKAVMFPTY Human13 HEFGHSLGLDHSKDPGALMFPIY Human14 HELGHALGLEHSSDPSAIMAPFY Human15 HELGHALGLEHSSNPNAIMAPFY Human16 HELGHALGLEHSNDPTAIMAPFY Human17 HEFGHAIGLSHVAAAHSIMRPYY Human19 HEVGHALGLGHSRYSQALMAPVY Human20 HEFGHALGLAHSTDPSALMYPTY Human21 HEIGHVLGLPHTYRTGSIMQPNY Human23 HEIGHALGIMHSQHGRALMHINA Human24 HELGHALGLEHSSDPSAIMAPFY Human25 HFFGHALGLGHSSAPNSIMRPFY Human26 HEIGHSLGLQHSGNQSSIMYPTY Human28 HEIGHTLGLTHSPAPRALMAPYY

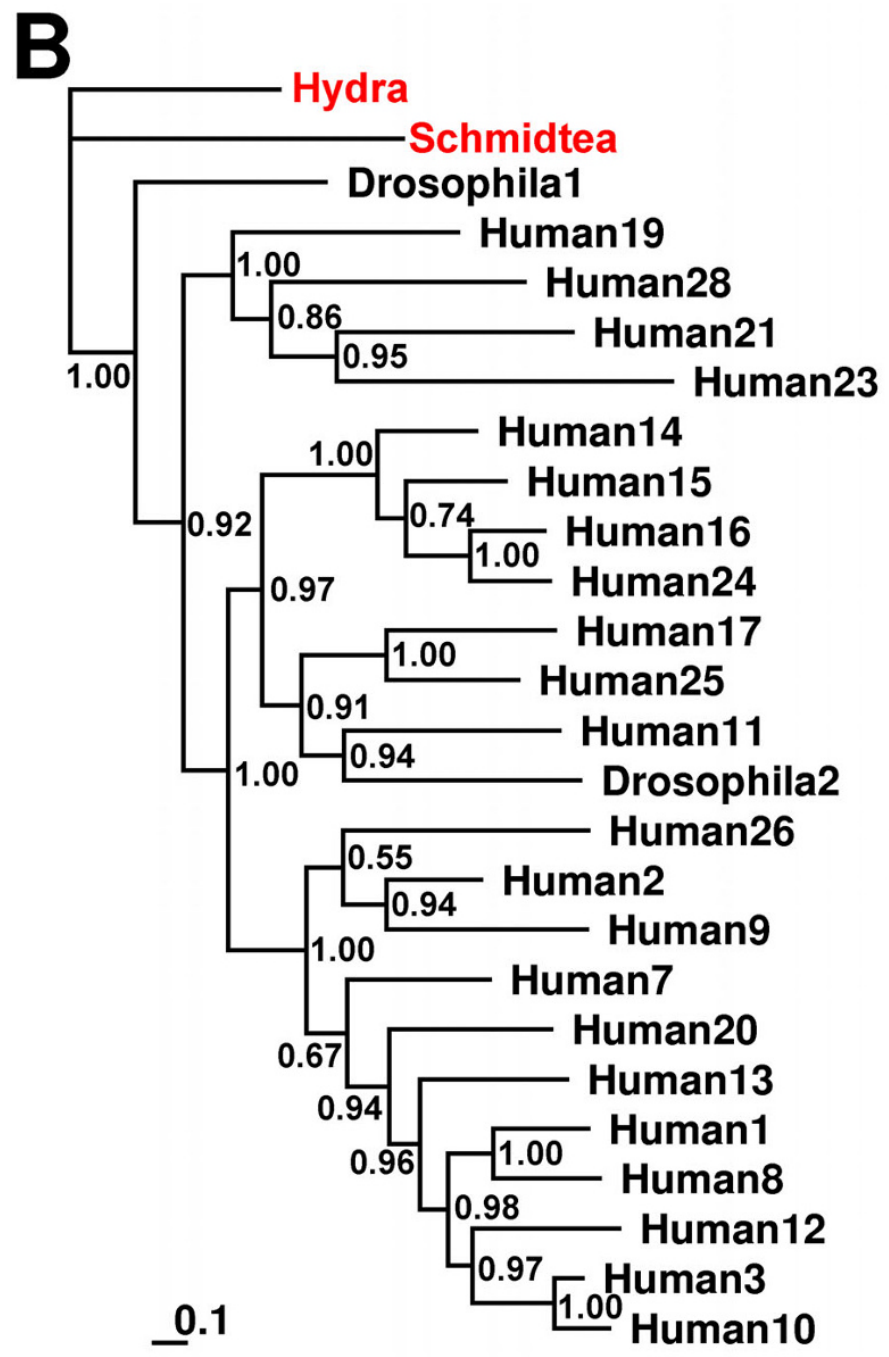

Figure 6

An identified Schmidtea MMP gene is related to Hydra MMP and to MMPs from insects and mammals. (A) All known MMPs from the fully genome sequenced ecdysozoan Drosophila melanogaster and humans (Deuterostomia) were aligned with the Schmidtea-MMP (AY068367) and the active site sequences are shown (MMP active site consensus sequence: HEXGHXXGXXHS). (B) A Bayesian protein tree was generated and we found that the Schmidtea-MMP grouped together with the MMP from $H$. vulgaris (AAD45804) nearest to MMP-I from D. melanogaster. UniProt accession numbers for MMPs are: Drosophila I, Q9GTK3; Drosophila2, Q8MPP3; Human 19, Q99542; Human28, Q9H239; Human II, P24347; Human2I, Q8NI 19; Human 17, Q9ULZ9; Human25, Q9NPA2; Human 14, P5028I; Human 15, P5I5II; Human 16, P5I5I2; Human24, Q9Y5R2; Human20, O60882; Human 12, P39900; Human 13, P45452; Human I, P03956; Human8, P22894; Human3, P08254; Human 10, P09238; Human7, P09237; Human26, Q9NREI; Human23, O75900; Human2, P08253; Human9, PI4780. Posterior probabilities are plotted at nodes. The scale bar represents the substitutions per site.

major vault protein and vWF protein in $H$. vulgaris). In addition, using the SSH-method we have recently identified novel insect antimicrobial peptides among which some of them emerged as promising templates for the rational design of second generation antibiotics [57] or as transgenes for the generation of disease-resistant crops [58]. Hence, identified immunity-related genes from
Schmidtea and Hydra may have also potential therapeutic value. Additionally, it will be a challenge to elucidate physiological functions of the presently identified genes during immune responses and homeostasis and to employ Schmidtea and Hydra as model organisms for the investigation of molecular interactions of pathogens with the host innate immune system. 


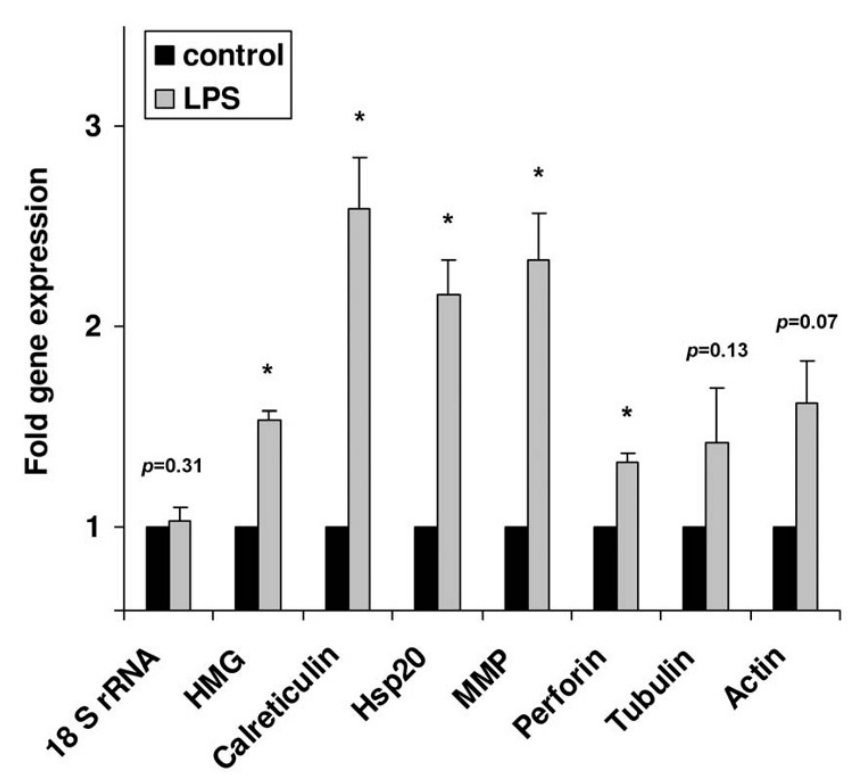

Figure 7

Quantitative real time RT-PCR analysis of selected Schmidtea genes that are up-regulated in response to septic wounding. The mRNA levels of selected genes in immune challenged animals (gray bars) were determined and are shown relative to their expression levels in untreated animals (black bars). The expression of the house-keeping gene I8S rRNA was not significantly influenced by the treatment. Results represent mean values of three independent determinations $\pm \mathrm{SD}$. Statistically significant differences were determined using Student's t-test and are indicated by asterisks $(p<0.05)$ or the determined $p$ values were inserted.

\section{Methods \\ Immune challenge of Schmidtea mediterranea and Hydra vulgaris and RNA isolation}

The asexual strain of $S$. mediterranea (originated from a fountain in Montjuïc, Barcelona, Spain) was kept at $18^{\circ} \mathrm{C}$ in darkness and fed once per week with sheep liver. Oneweek-starved about 7-mm-long animals were used for experiments. H. vulgaris (Zürich strain, originally isolated by $\mathrm{P}$. Tardent) was cultured at $18^{\circ} \mathrm{C}$ as described [59]. Septic wounding was performed by dissecting animals in two parts using a scalpel in the presence of $50 \mu \mathrm{g} / \mathrm{ml} \mathrm{LPS}$ (purified Escherichia coli endotoxin 0111:B4, Cat. No.: L2630, Sigma, Taufkirchen, Germany). Total RNA was extracted from $14 \mathrm{~h}$ post immune challenged animals using the TriReagent isolation reagent (Molecular Research Centre, Cincinnati, Ohio, USA) according to the instructions of the manufacturer. RNA integrity was confirmed by ethidium bromide gel staining and quantities were determined spectrophotometrically.

\section{Construction of subtracted cDNA libraries using the SSH method}

In order to identify genes that are differentially expressed in response to septic injury we performed the suppression subtractive hybridization method using RNAs from immune challenged and untreated $S$. mediterranea and $H$. vulgaris, respectively, the SMART PCR cDNA synthesis Kit (Clontech, Mountain View, CA, USA), and the PCR-Select cDNA subtraction Kit (Clontech), according to the protocols of the manufacturer. Colony PCR of each 288 randomly picked colonies and blot hybridization have been performed similar as described recently [19].

Sequencing and computer analysis of CDNA sequence data Plasmid isolation of positively screened colonies was performed with the FastPlasmid Mini Kit (Eppendorf, Hamburg, Germany) and purified plasmids were custom sequenced by Macrogen Inc. (Seoul, South-Korea). Blast [60] was used to identify corresponding gene sequences in the public sequence databases. InterProScan [61] was used for an integrated search in PROSITE, Pfam, and PRINTS databases at EMBL-European Bioinformatics Institute and to predict signal sequences and transmembrane regions.

\section{Sequence alignments and phylogenetic analysis}

Multiple sequence alignments were computed using blosum62 program [62]. For phylogenetic reconstruction, we used the software package MrBayes 3.1.2 [63] which combines Bayesian inference and Markov chain Monte Carlo convergence acceleration techniques known as Metropolis coupling. The best fixed-rate model of amino acid evolution was determined by model jumping among nine possible models. The model with the overall highest posterior probability was WAG model [64] for the MMPs after $10^{6}$ generations and for calreticulins after $2 \times 10^{6}$ generations. We used convergence diagnostic (i.e., the standard deviation of split frequencies) to determine whether the run length is sufficient. The average standard deviation of split frequencies was 0.0051 for MMPs and 0.0023 for the calreticulins. This indicated that the two chains that were run converged on similar results in all cases. The $50 \%$ majority rule tree presented here was constructed from all sampled trees with the first $25 \%$ of all trees ignored as burn in. Posterior probabilities plotted at the nodes can be interpreted as the probability that the tree or clade is correct [65].

\section{Quantitative real-time PCR}

Quantitative real time RT-PCR was performed with the real-time PCR system Mx3000P (Stratagene, La Jolla, California, USA) using the FullVelocity $\mathrm{SYBR}^{\circledR}$ Green QRTPCR Master Mix (Stratagene), according to the protocols of the manufacturer. $50 \mathrm{pg}$ of RNA per reaction were used to amplify $18 \mathrm{~S}$ rRNA and $50 \mathrm{ng}$ of RNA per reaction to 
Table 3: Genes analyzed by quantitative real time RT-PCR.

\begin{tabular}{llll}
\hline \multicolumn{1}{c}{ Gene } & accession number & Forward primer 5'-3' & Reverse primer 5'-3' \\
\hline I8S rRNA & $\underline{E G 412600}$ & ATGGTTGCAAAGCTGAAACT & TCCCGTGTTGAGTCAAATTA \\
HMG & $\underline{E E 666986}$ & CGCATCTGATCCATGCAAGC & TGTACCTCCCCCGATTGTTCC \\
Calreticulin & $\underline{E G 417940}$ & CCCTTGGGTGCATCCAGAAA & CGGACTTCACCTGCCACAGA \\
Hsp20 & $\underline{\text { DN302574 }}$ & GGAATCTGGGGTGAGCTTGG & CGGTTGATGGCTCAATGCAC \\
MMP & $\underline{\text { AY068367 }}$ & TCGGCTTCTGGTTCCGATGT & CGGGCAAAAGCTGCAGAACT \\
Perforin & $\underline{\text { DN307006 }}$ & GGCTGCCTGCATCTGTTTGA & TTGAGCCGTAGTCCGCCAAT \\
Tubulin & $\underline{\text { DN315207 }}$ & TCCGGGTGGAGATTTGGCTA & GCACGCTTGGCATACATTAGGTC \\
Actin & $\underline{E C 386294}$ & ATCCTGGCATTGCTGATCGT & TGGGGGAGCAACAATCTTGA \\
\hline
\end{tabular}

amplify selected Schmidtea-genes using appropriate primers (Table 3). Primers were selected using the primer3 software [66] and were purchased from Thermo electron (Waltham, MA, USA).

\section{Competing interests}

The authors declare that they have no competing interests.

\section{Authors' contributions}

BA designed and carried out the experiments, performed the analyses, and drafted parts of the manuscript. AV participated in its design and coordination, and drafted parts of the manuscript. All authors read and approved the final manuscript.

\section{Acknowledgements}

We thank Meike Fischer for excellent technical assistance and Katja Altincicek for critical reading of the manuscript. We are grateful to Emili Saló (University of Barcelona, Spain) and Luca Gentile (Max Planck Institute for Molecular Biomedicine, Münster, Germany) for kindly providing us with Schmidtea mediterranea and Monika Hassel (Philipps University of Marburg, Germany) for kindly providing us with Hydra vulgaris.

\section{References}

I. Sánchez Alvarado A, Tsonis PA: Bridging the regeneration gap: genetic insights from diverse animal models. Nat Rev Genet 2006, 7( I I ):873-884.

2. Egger $B$, Gschwentner R, Rieger R: Free-living flatworms under the knife: past and present. Dev Genes Evol 2007, 2 I 7(2):89-I 04.

3. Saló $E$ : The power of regeneration and the stem-cell kingdom: freshwater planarians (Platyhelminthes). Bioessays 2006, 28(5):546-559.

4. Reddien PW, Sánchez Alvarado A: Fundamentals of planarian regeneration. Annu Rev Cell Dev Biol 2004, 20:725-757.

5. Bosch TC: Why polyps regenerate and we don't: towards a cellular and molecular framework for Hydra regeneration. Dev Biol 2007, 303(2):42I-433.

6. Khalturin K, Anton-Erxleben F, Milde S, Plötz C, Wittlieb J, Hemmrich G, Bosch TC: Transgenic stem cells in Hydra reveal an early evolutionary origin for key elements controlling self-renewal and differentiation. Dev Biol 2007, 309(I):32-44.

7. González-Estévez C, Momose T, Gehring WJ, Saló E: Planarian transgenic lines obtained by electroporation using transposon-derived vectors and an eye-specific GFP marker. Proc Natl Acad Sci USA 2003, 100: 1 4046- 14051.

8. Newmark PA, Reddien PW, Cebria F, Sánchez Alvarado A: Ingestion of bacterially expressed double-stranded RNA inhibits gene expression in planarians. Proc Natl Acad Sci USA 2003, 100(Suppl I): I |86I-I I865.

9. Sánchez Alvarado A, Newmark PA: Double-stranded RNA specifically disrupts gene expression during planarian regeneration. Proc Natl Acad Sci USA 1999, 96:5049-5054.
10. Lohmann JU, Endl I, Bosch TC: Silencing of developmental genes in Hydra. Dev Biol 1999, 2 I 4(1):2I I-2 14.

II. Wittlieb J, Khalturin K, Lohmann JU, Anton-Erxleben F, Bosch TC: Transgenic Hydra allow in vivo tracking of individual stem cells during morphogenesis. Proc Natl Acad Sci USA 103(|6):6208-62 | I. 2006, Apr 18;

12. Altincicek B, Vilcinskas A: Identification of immune-related genes from an apterygote insect, the firebrat Thermobia domestica. Insect Biochem Mol Biol 2007, 37:726-73I.

13. Altincicek B, Vilcinskas A: Analysis of the immune-inducible transcriptome from microbial stress resistant, rat-tailed maggots of the drone fly Eristalis tenax. BMC Genomics 2007, 8:326.

14. Altincicek B, Knorr E, Vilcinskas A: Beetle immunity: Identification of immune-inducible genes from the model insect Tribolium castaneum. Dev Comp Immunol 2008, 32:585-595.

15. Seitz V, Clermont A, Wedde M, Hummel M, Vilcinskas A, Schlatterer $\mathrm{K}$, Podsiadlowski L: Identification of immunorelevant genes from greater wax moth (Galleria mellonella) by a subtractive hybridization approach. Dev Comp Immunol 2003, 27:207-2 I5.

16. Ursic-Bedoya RJ, Lowenberger CA: Rhodnius prolixus : identification of immune-related genes up-regulated in response to pathogens and parasites using suppressive subtractive hybridization. Dev Comp Immunol 2007, 3 I (2): I09-120.

17. Zhu Y, Johnson TJ, Myers AA, Kanost MR: Identification by subtractive suppression hybridization of bacteria-induced genes expressed in Manduca sexta fat body. Insect Biochem Mol Biol 2003, 33:54I-559.

18. de Lorgeril J, Saulnier D, Janech MG, Gueguen Y, Bachère E: Identification of genes that are differentially expressed in hemocytes of the Pacific blue shrimp (Litopenaeus stylirostris) surviving an infection with Vibrio penaeicida. Physiol Genomics 2005, 2 I (2): 174-183.

19. Altincicek B, Vilcinskas A: Analysis of the immune-related transcriptome of a lophotrochozoan model, the marine annelid Platynereis dumerilii. Front Zool 2007, 4:18.

20. Bouchut A, Coustau C, Gourbal B, Mitta G: Compatibility in the Biomphalaria glabrata/Echinostoma caproni model: new candidate genes evidenced by a suppressive subtractive hybridization approach. Parasitology 2007, 134:575-588.

21. Guillou F, Mitta G, Galinier R, Coustau C: Identification and expression of gene transcripts generated during an anti-parasitic response in Biomphalaria glabrata. Dev Comp Immunol 2007, 31 1:657-67I.

22. Tanguy A, Guo $X$, Ford SE: Discovery of genes expressed in response to Perkinsus marinus challenge in Eastern (Crassostrea virginica) and Pacific (C. gigas) oysters. Gene 2004, 338: $|2|-|3|$.

23. Huang G, Liu H, Han Y, Fan L, Zhang Q, Liu J, Yu X, Zhang L, Chen S, Dong $M$, Wang $L, X u A$ : Profile of acute immune response in Chinese amphioxus upon Staphylococcus aureus and Vibrio parahaemolyticus infection. Dev Comp Immunol 2007, 3I:1013-1023.

24. Lin B, Chen S, Cao Z, Lin Y, Mo D, Zhang H, Gu J, Dong M, Liu Z, Xu $\mathrm{A}$ : Acute phase response in zebrafish upon Aeromonas salmonicida and Staphylococcus aureus infection: Striking similarities and obvious differences with mammals. Mol Immunol 2007, 44:295-30I. 
25. Robb SM, Ross E, Sánchez Alvarado A: SmedGD: the Schmidtea mediterranea genome database. Nucleic Acids Res 2007. doi:10.1093/nar/gkm684

26. Comparative Genomics Platform for Basal Metazoa [http:// www.compagen.org]

27. Akira S, Uematsu S, Takeuchi O: Pathogen recognition and innate immunity. Cell 2006, I24(4):783-80I.

28. Knaus UG, Morris S, Dong HJ, Chernoff J, Bokoch GM: Regulation of human leukocyte p2 I-activated kinases through $\mathbf{G}$ protein - coupled receptors. Science 1995, 269(522I):22I-223.

29. Waetzig V, Herdegen T: Context-specific inhibition of JNKs: overcoming the dilemma of protection and damage. Trends Pharmacol Sci 2005, 26(9):455-46।.

30. Feske S: Calcium signalling in lymphocyte activation and disease. Nat Rev Immunol 2007, 7(9):690-702.

31. Bansal D, Campbell KP: Dysferlin and the plasma membrane repair in muscular dystrophy. Trends Cell Biol 2004 | 4(4):206-2I3.

32. Ryeom S, Greenwald RJ, Sharpe AH, McKeon F: The threshold pattern of calcineurin-dependent gene expression is altered by loss of the endogenous inhibitor calcipressin. Nat Immuno 2003, 4(9):874-88I.

33. Cardenas ME, Hemenway C, Muir RS, Ye R, Fiorentino D, Heitman : Immunophilins interact with calcineurin in the absence of exogenous immunosuppressive ligands. EMBO J 1994, I 3(24):5944-5957.

34. Sakane F, Imai S, Kai M, Yasuda S, Kanoh H: Diacylglycerol kinases: why so many of them? Biochim Biophys Acta 2007, I 77|(7):793-806.

35. Johnson S, Michalak M, Opas M, Eggleton P: The ins and outs of calreticulin: from the ER lumen to the extracellular space. Trends Cell Biol 200I, I I(3): I22-I 29.

36. Gao B, Adhikari R, Howarth M, Nakamura K, Gold MC, Hill AB, Knee $\mathrm{R}$, Michalak $M$, Elliott $\mathrm{T}$ : Assembly and antigen-presenting function of MHC class I molecules in cells lacking the ER chaperone calreticulin. Immunity 2002, I 6(I):99-109.

37. Desmots F, Russell HR, Michel D, McKinnon PJ: Scythe regulates apoptosis inducing factor stability during endoplasmic reticulum stress induced apoptosis. I Biol Chem 2007. doi/l0.1074/ jbc.M706419200

38. Wiens M, Korzhev M, Krasko A, Thakur NL, Peroviæ-Ottstadt S, Breter HJ, Ushijima H, Diehl-Seifert B, Müller IM, Müller WE: Innate immune defense of the sponge Suberites domuncula against bacteria involves a MyD88-dependent signaling pathway. Induction of a perforin-like molecule. J Biol Chem 2005, 280(30):27949-27959.

39. Miller DJ, Hemmrich G, Ball EE, Hayward DC, Khalturin K, Funayama $\mathrm{N}$, Agata $\mathrm{K}$, Bosch TC: The innate immune repertoire in cnidaria - ancestral complexity and stochastic gene loss. Genome Biol 2007, 8(4):R59.

40. van Loon LC, Rep M, Pieterse CM: Significance of inducible defense-related proteins in infected plants. Annu Rev Phytopathol 2006, 44:135-162.

41. Cheng N, He R, Tian J, Dinauer MC, Ye RD: A Critical Role of Protein Kinase C\{delta\} Activation Loop Phosphorylation in Formyl-Methionyl-Leucyl-Phenylalanine-Induced Phosphorylation of p47phox and Rapid Activation of Nicotinamide Adenine Dinucleotide Phosphate Oxidase. J Immunol 2007, I 79(I I):7720-7728.

42. Kowalski MP, Dubouix-Bourandy A, Bajmoczi M, Golan DE, Zaidi T, Coutinho-Sledge YS, Gygi MP, Gygi SP, Wiemer EA, Pier GB: Host resistance to lung infection mediated by major vault protein in epithelial cells. Science 2007, 3 I 7(5834): $130-132$

43. Fraune S, Bosch TC: Long-term maintenance of species-specific bacterial microbiota in the basal metazoan Hydra. Proc Natl Acad Sci USA 2007, I 04(32): |3 |46-13151.

44. Matzinger $P$ : The danger model: a renewed sense of self. Science 2002, 296(5566):30I-305.

45. Altincicek B, Vilcinskas A: Metamorphosis and collagen-IV-frag ments stimulate innate immune response in the greater wax moth, Galleria mellonella. Dev Comp Immunol 2006, 30( I 2): I I08-III8.

46. Altincicek B, Linder M, Linder D, Preissner KT, Vilcinskas A: Microbial metalloproteinases mediate sensing of invading pathogens and activate innate immune responses in the lepidopteran model host Galleria mellonella. Infect Immun 2007, 75(I): $175-183$

47. Kusserow A, Pang K, Sturm C, Hrouda M, Lentfer J, Schmidt HA, Technau U, von Haeseler A, Hobmayer B, Martindale MQ, Holstein TW: Unexpected complexity of the Wnt gene family in a sea anemone. Nature 2005, 433(7022): I56-I60.

48. Guder C, Pinho S, Nacak TG, Schmidt HA, Hobmayer B, Niehrs C, Holstein TW: An ancient Wnt-Dickkopf antagonism in Hydra. Development 2006, I33(5):901-9II.

49. Stoick-Cooper CL, Moon RT, Weidinger G: Advances in signaling in vertebrate regeneration as a prelude to regenerative medicine. Genes Dev 2007, 2 I (I I):1292-1315.

50. Leontovich AA, Zhang J, Shimokawa K, Nagase H, Sarras MP Jr: A novel hydra matrix metalloproteinase (HMMP) functions in extracellular matrix degradation, morphogenesis and the maintenance of differentiated cells in the foot process. Development 2000, I27(4):907-920.

5I. Shimizu H, Zhang X, Zhang J, Leontovich A, Fei K, Yan L, Sarras MP Jr: Epithelial morphogenesis in hydra requires de novo expression of extracellular matrix components and matrix metalloproteinases. Development 2002, I29(6): | 52 |-I532.

52. Page-McCaw A, Ewald AJ, Werb Z: Matrix metalloproteinases and the regulation of tissue remodelling. Nat Rev $\mathrm{Mol} \mathrm{Cell} B i o l$ 2007, 8(3):221-233.

53. Parks WC, Wilson CL, Lopez-Boado YS: Matrix metalloproteinases as modulators of inflammation and innate immunity. Nat Rev Immunol 2004, 4:617-629.

54. Altincicek B, Vilcinskas A: Identification of a lepidopteran matrix metalloproteinase with dual roles in metamorphosis and innate immunity. Dev Comp Immunol 2008, 32(4):400-409.

55. Ruggeri ZM: Von Willebrand factor: looking back and looking forward. Thromb Haemost 2007, 98(I):55-62.

56. Wiens $M$, Korzhev M, Perovic-Ottstadt S, Luthringer B, Brandt D, Klein S, Müller WE: Toll-like receptors are part of the innate immune defense system of sponges (demospongiae: Porifera). Mol Biol Evol 2007, 24(3):792-804

57. Wedde M, Weise C, Nuck R, Altincicek B, Vilcinskas A: The insect metalloproteinase inhibitor gene of the lepidopteran Galleria mellonella encodes two distinct inhibitors. Biol Chem 2007 388(I): I I9- I 27

58. Langen G, Imani J, Altincicek B, Kieseritzky G, Kogel KH, Vilcinskas A: Transgenic expression of gallerimycin, a novel antifungal insect defensin from the greater wax moth Galleria mellonella, confers resistance to pathogenic fungi in tobacco. Biol Chem 2006, 387(5):549-557.

59. Hassel M, Bridge DM, Stover NA, Kleinholz H, Steele RE: The level of expression of a protein kinase $\mathbf{C}$ gene may be an important component of the patterning process in Hydra. Dev Genes Evol 1998, 207(8):502-5I4.

60. Basic Local Alignment Search Tool [http:// www.ncbi.nlm.nih.gov/BLAST/]

61. InterProScan Sequence Search [http://www.ebi.ac.uk/InterPro Scan/]

62. Corpet F: Multiple sequence alignment with hierarchical clustering. Nucl Acids Res 1988, I 6:10881-10890.

63. Ronquist F, Huelsenbeck JP: MrBayes 3, Bayesian phylogenetic inference under mixed models. Bioinformatics 2003, I9:1572-1574.

64. Whelan S, Goldman N: A general empirical model of protein evolution derived from multiple protein families using a maximum-likelihood approach. Mol Biol Evol 200I, I 8:69I-699.

65. Huelsenbeck J, Rannala B: Frequentist properties of Bayesian posterior probabilities of phylogenetic trees under simple and complex substitution models. Syst Biol 2004, 53:904-913.

66. Rozen S, Skaletsky H: Primer3 on the WWW for general users and for biologist programmers. Bioinformatics Methods and Protocols: Methods in Molecular Biology. Humana Press, Totowa, NJ; 2000

67. Wang Z, Wang G: APD: An antimicrobial peptide database. Nucleic Acids Res 2004, 32:D590-D592. 